\title{
The Impact of Internet Finance to Commercial Banks in China
}

\author{
Meng $\mathrm{Wu}^{*}$
}

University of Glasgow, Shanghai 201204, China. E-mail: cindy-wm@hotmail.com

\begin{abstract}
In recent years, network technology, information technology and data processing technology have become the basis of the competition of Internet financial institutions. With the rapid development of the electronic platform, the accumulation of massive customer data information, Internet finance has a more and broader range of customer resources than that of a single bank. These advantages of Internet finance will have a significant impact on commercial banks. The traditional banks have a mature business model and rich industry experience in finance. Internet finance and traditional commercial banks interact with each other. In this case, this paper will focus on the influence of Internet finance on traditional commercial banks in China.
\end{abstract}

Keywords: Internet Finance; Commercial Banks; STATA

\section{Introduction}

Internet finance is defined as "the provision of financial services and markets using electronic communication and computation" (Franklin Allen, 2002) ${ }^{[1]}$. In 2014, Liu claimed that internet finance could integrate internet technologies and financial activities. It can also play a significant role in four main sections: risk management, payment and settlement, source allocation and networking channels ${ }^{[2]}$. In 2002, Furst claimed that the banks are more likely to offer the transactional Internet business if they are large, have a good run, located in urban areas, have expensive branch network expenses and have large non-interest income ${ }^{[3]}$. In 2014, Tian Xiong claimed that the most significant difference between Internet finance and traditional finance is the difference in the basic theory of economics. The traditional finance is based on the Pareto Principle, while Internet finance is based on the platform economy and the long tail theory. The above documents have a remarkable contribution to the understanding of Internet finance. While the discussion of the combination of Internet financial and commercial banks are rare. This paper will collect accurate data in Internet finance in the past few years and use this index to conduct a quantitative analysis of Internet financial development in China $^{[4]}$.

\section{Data and methodology}

\subsection{Data and sample source}

Until August 2007, Alipay had more than 47 million users in China, growing at a rate of more than 80,000 new registered users each day. And Alipay's average daily transaction volume exceeds RMB 150 million, handing an average of 780,000 transactions each day. Therefore, this paper spans the 2005-2015 period. This paper chooses 16 commercial banks in China as research objects. The data is selected from 2006 to 2015. It deletes some of the missing samples, and finally getting the effective sample size is 146 .

This is an open-access article distributed under the terms of the Creative Commons Attribution Non-Commercial License (http://creativecommons.org/licenses/by-nc/4.0/), which permits unrestricted non-commercial use, distribution, and reproduction in any medium, provided the original work is properly cited. 


\subsection{Variables}

Table 1. Variables description table

\begin{tabular}{|l|l|l|}
\hline Type the variables & Meaning & Code \\
\hline Explained Variables & Return on Assets & ROA \\
\hline Explanatory Variables & Growth of Internet Finance & GIF \\
\hline Control Variable & Capital Adequacy Ratio & CAR \\
\hline & Cost to income ratio & CIR \\
\hline & total assets (after taking logarithm) & ASSET \\
\hline & Net Interest Margin & NIM \\
\hline & Gross Domestic Product & GDP \\
\hline & Consumer Price Index & CPI \\
\hline
\end{tabular}

\subsection{Methodology}

As the variables have been explained in above, this paper builds the model as follows: $R O A_{\mathrm{it}}=\alpha_{\mathrm{i}}+\mathrm{b}_{1} \mathrm{gIF}_{\mathrm{it}}+\mathrm{b}_{2} \mathrm{CAR}_{\mathrm{it}}+\mathrm{b}_{3} \mathrm{CIR}_{\mathrm{it}}+\mathrm{b}_{4} \mathrm{ASSET}_{\mathrm{it}}+\mathrm{b}_{5} \mathrm{NIM}_{\mathrm{it}}+\mathrm{b}_{6} \mathrm{GDP}_{\mathrm{it}}+\mathrm{b}_{7} \mathrm{CPI}_{\mathrm{it}}+\mu_{\mathrm{it}}$

The $\alpha_{\mathrm{i}}$ represents individual differences of different commercial banks. The $\mu_{\mathrm{it}}$ stands for the error term. Then I stand for the provinces and the $\mathrm{T}$ stand for the year. To build a model to test the impact of Internet finance on commercial banks, first of all, variables need to be tested for smoothness, having the unit root test for each variable before to have the regression. This paper is non-balanced panel data because of part of the commercial banks listed late, using the fisher test verifies the existence of unit root.

Table 2. Fisher test

\begin{tabular}{|l|l|l|l|}
\hline Variable & Statistics & P-Value & Conclusion \\
\hline ROA & 126.4104 & 0.0000 & Stable \\
\hline GIF & 140.1444 & 0.0000 & Stable \\
\hline CAR & 177.1889 & 0.0000 & Stable \\
\hline CIR & 121.8976 & 0.0000 & Stable \\
\hline ASSET & 66.6610 & 0.0003 & Stable \\
\hline NIM & 73.9214 & 0.0000 & Stable \\
\hline GDP & 60.0707 & 0.0019 & Stable \\
\hline CPI & 102.7599 & 0.0000 & Stable \\
\hline
\end{tabular}

From the above table, each of the variables is rejected at a significant level of $1 \%$ of the original hypothesis of the unit root, and the original sequence is stable. These explanations of the above variables are stable, so the above variables can directly be used to have the regression.

The used variables are panel data, which refers to take multiple cross-sections in the time series. The sample observations formed by the sample data are selected in these cross-sections. There are two dimensions of the time series and the cross-section. When the data is arranged in the two dimensions, it is put in a plane with only one size of data set in a line is different. When using the panel data to estimate, we must determine which model is the more appropriate choice. In general, the $\mathrm{F}$ statistics are used to test.

$\mathrm{F}=\frac{\left(S S E_{1}-S S E_{2}\right)(N-1)}{S S E_{2} /(N T-N-K)} \sim F(N-1, N T-N-K)$

Among them, the $S S E_{1}$ and $S S E_{2}$ represent the sum of the residuals of the mixed regression model, and in the fixed effects regression model, $\mathrm{T}$ stands for the number of periods, $\mathrm{K}$ stands for the number of explanatory variables, 
and $\mathrm{N}$ stands for the number of cross-sections. Through the test of $\mathrm{F}$ value determine whether the use of a mixed model or fixed effects regression model. What's more, the fixed effects regression models are divided into the individual fixed effects regression model and individual random effects regression models. Through the test of $\mathrm{F}$ value determines whether the use of a mixed model or fixed effects regression model.

Because it is the panel data, this paper uses the least squares model to regression. And then, the Hausman Test should be used to determine whether a fixed effects regression model or a random-effects regression model should be established. The Hausman Test's original hypothesis is that the random effects regression model is consistent with the estimation of the fixed effects regression model. The random effects are more effective, and the random effect regression model should be established. Through the LR test and the Hausman test, the Hausman test application is more common in general. Like the following, it is the original hypothesis:

$H_{0}=\hat{\beta}_{F E}=\hat{\beta}_{R E}$

Using statistics:

$\lambda^{2}=\left(\hat{\beta}_{F E}-\hat{\beta}_{R E}\right)^{\prime} V\left(\hat{\beta}_{F E}-\hat{\beta}_{R E}\right)^{-1}\left(\hat{\beta}_{F E}-\hat{\beta}_{R E}\right) \stackrel{\text { Asym }}{\longrightarrow} \lambda^{2}(K)$

In which $\hat{\beta}_{F E}$ and $\hat{\beta}_{R E}$ represent the estimated coefficient of the fixed effects model and the random-effects model, respectively. $\mathrm{K}$ is the number of explanatory variables. If $\mathrm{H}$ exceeds a certain threshold, the individual fixed effects model should be selected. Otherwise, the individual random effects model should be chosen.

Table 2 in the following is describing the statistics. $\mathrm{N}$ stands for the sample size, mean stands for the average of the sample, sd stands for the standard deviation. ROA is the return on assets. GIF is the growth of the Internet finance. CAR is the capital adequacy ratio. CIR is the cost to income ratio. NIM is the net interest margin. GDP is the gross domestic product. CPI is the consumer price index. ASSET is the total assets (after taking logarithm).

Table 3. Describe the statistics

\begin{tabular}{|l|l|l|l|l|l|}
\hline Variable & N & Mean & Sd & Min & Max \\
\hline ROA & 146 & 0.0110 & 0.00234 & 0.00364 & 0.0149 \\
\hline GIF & 146 & 1.721 & 2.790 & 0.417 & 10.13 \\
\hline CAR & 146 & 0.124 & 0.0320 & 0.0577 & 0.307 \\
\hline CIR & 146 & 0.335 & 0.0546 & 0.219 & 0.463 \\
\hline NIM & 146 & 0.0232 & 0.00271 & 0.0181 & 0.0298 \\
\hline GDP & 146 & 0.0937 & 0.0217 & 0.0690 & 0.142 \\
\hline CPI & 146 & 1.029 & 0.0189 & 0.993 & 1.059 \\
\hline ASSET & 146 & 28.43 & 1.324 & 25.05 & 30.66 \\
\hline
\end{tabular}

From the above Table 3, the total return on assets of the mean value is 0.0110 , which stands the Chinese listed commercial banks profitable is low. The Internet finance growth rate of the mean value is 1.721 , which indicates that the third-party payment growth rate is $172.1 \%$ on average, indicating that Internet finance has rapid development in recent years. At the same time, the max value of Internet finance growth rate is 10.13. The min value of the Internet finance growth rate is 0.417 , indicating that the gap between the year of the Internet finance rate is huge. The mean of the capital adequacy ratio is 0.124 , with the maximum is 0.307 and the minimum is 0.0577 , which shows a huge gap between the different commercial banks in the capital adequacy ratio. The mean of the cost to income ratio is 0.335 , which means that the sample listed commercial banks' average cost is $33.5 \%$. The net interest margin is 0.0232 . The gross domestic product is 0.0937 , which indicates that the development of the Chinese economy is rapid, with the minimum and maximum are 0.0690 and 0.142 , respectively, which means that the development of the Chinese economy has risen stably. The average consumer price index is 1.029 , indicating that China is experiencing moderate inflation on average. The maximum asset size is 30.66 and the minimum value is 25.05 , which indicates that the assets of different listed commercial banks have a vast difference. 


\section{Results and analysis}

\subsection{Results}

In the Table 4, the $*$ represents a significant correlation of $10 \%$, the $* *$ represents a significant correlation of $5 \%$ and the $* * *$ stands for a significant correlation of $1 \%$.

As can be seen from the above Table 4, the $-0.158 *$ stands for the rate of the growth of Internet finance and the total assets yield are negative correlative at the 10\% significant level, which indicates that the increase of the Internet finance size will reduce the rate of profitability of the commercial banks. From the view of the control variables, the $0.470 * * *$ means that the capital adequacy ratio is significant at the $1 \%$ significance level. The coefficient is positive, which indicates that the increase in the capital adequacy ratio will significantly increase the profitability of the commercial banks. The $-0.526^{* * *}$ stands for that the cost to income is significant at the $1 \%$ significance level; while the coefficient is negative, which shows that the increase of the cost to income ratio will dramatically decrease the commercial banks' profitability. The $0.318^{* * *}$ stands for the net interest margin is significant at $1 \%$ significance level, with the coefficient positive, which shows that the increase in the net interest margin will remarkably increase the commercial banks' profitability. The $-0.314 * * *$ in the table shows that the rate of the gross domestic product is significant at $1 \%$ significance level, while the coefficient is negative. In other word, it indicates that the increase of the rate of the gross domestic product will reduce the profitability of the commercial banks. Simultaneously, the $0.165^{* *}$ stands for the consumer price index is significant at the 5\% significance level. With the coefficient is positive, the meaning of that is the increase of the consumer price index will dramatically increase the profitability of the commercial banks. The $0.263 * * *$ stands for the total asset of the commercial banks is significant at the $1 \%$ significance level and the coefficient is positive. At the same time, the total asset of the commercial banks stands for the size of the commercial banks. Thus, the $0.263 * * *$ shows that the increase of the size of the commercial banks' scale will increase the profitability of the commercial banks. In a word, the larger the commercial banks are, the better profitability ability they have.

Table 4. The variables

\begin{tabular}{|l|l|l|l|l|l|l|l|l|}
\hline & ROA & GIF & CAR & CIR & NIM & GDP & CPI & ASSET \\
\hline ROA & 1 & & & & & & \\
\hline GIF & $-0.158^{*}$ & 1 & & & & & \\
\hline CAR & $0.470^{* * *}$ & 0.124 & 1 & & & & & \\
\hline CIR & $-0.526 * * *$ & $-0.280^{* * *}$ & $-0.398^{* * *}$ & 1 & & & & \\
\hline NIM & $0.318^{* * *}$ & $0.268^{* * *}$ & $0.142^{*}$ & 0.0690 & 1 & & & \\
\hline GDP & $-0.314^{* * *}$ & 0.111 & 0.0110 & $0.476^{* * *}$ & $0.153^{*}$ & 1 & & \\
\hline CPI & $0.165^{* *}$ & $0.565^{* * *}$ & $0.164^{* *}$ & 0.0290 & $0.475^{* * *}$ & $0.362^{* * *}$ & 1 & \\
\hline ASSET & $0.263^{* * *}$ & $0.158^{*}$ & -0.0670 & $-0.298^{* * *}$ & -0.0240 & $-0.365^{* * *}$ & -0.130 & 1 \\
\hline
\end{tabular}

Because it is the panel data, this paper using the least-squares model to regression, and then, the Hausman Test should be used to determine whether a fixed effects regression model or a random-effects regression model should be established. The $*$ represents a significant correlation of $10 \%$. The $* *$ represents a significant correlation of $5 \%$. And the *** stands for a significant correlation of $1 \%$.

Multiple collinear tests were performed on each variable before regression. The VIE value (variance expansion factor) of each variable is less than 5, indicating no serious collinearity in the independent variable. Then the regression analysis can be carried out. The F-test and the Hausman test should be tested before the regression to determine the model's form, that is, using the random effects regression model or the fixed effects regression model.

In the above Table 5, the F value of the fixed effects model is 4.79. The corresponding P value of the fixed effects model is 0.0000 , which indicates that there is no significant difference between the original hypothesis of individual differences, and the fixed effects model is better than the ordinary least squares regression (OLS). The Hausman test 
statistic is 10.83 and the corresponding $\mathrm{P}$ value is 0.1463 . It cannot significantly reject the original hypothesis that the estimate is consistent, which indicates that the random-effects model should be used.

Table 5. Hausman test and F test

\begin{tabular}{|l|l|l|l|}
\hline Model & F value & Hausman value & P value \\
\hline Fixed effects model & 4.79 & -- & 0.0000 \\
\hline Random effects model & -- & 10.83 & 0.1463 \\
\hline
\end{tabular}

Table 6. Results

\begin{tabular}{|c|c|c|c|}
\hline VARIABLES & (1) Ols ROA & (2) Fe ROA & (3) Re ROA \\
\hline \multirow[t]{2}{*}{ GIF } & $-0.000196^{* * *}$ & $-0.000215 * * *$ & $-0.000183 * * *$ \\
\hline & $(-2.944)$ & $(-3.098)$ & $(-3.024)$ \\
\hline \multirow[t]{2}{*}{ CAR } & $0.0221 * * *$ & $0.0174 * * *$ & $0.0176^{* * *}$ \\
\hline & $(2.854)$ & $(3.437)$ & $(3.673)$ \\
\hline \multirow[t]{2}{*}{ CIR } & $-0.0140 * * *$ & -0.00669 & $-0.0111 * * *$ \\
\hline & $(-3.946)$ & $(-1.330)$ & $(-2.733)$ \\
\hline \multirow[t]{2}{*}{ NIM } & $0.252 * * *$ & $0.174 * * *$ & $0.163 * * *$ \\
\hline & $(3.569)$ & $(2.626)$ & $(2.800)$ \\
\hline \multirow[t]{2}{*}{ GDP } & $-0.0275 * * *$ & -0.0185 & $-0.0286 * * *$ \\
\hline & $(-2.767)$ & $(-1.553)$ & $(-3.450)$ \\
\hline \multirow[t]{2}{*}{ CPI } & $0.0286^{*}$ & $0.0389 * * *$ & $0.0353 * * *$ \\
\hline & $(1.948)$ & $(3.967)$ & $(3.643)$ \\
\hline \multirow[t]{2}{*}{ ASSET } & $0.000294 * *$ & $0.00115^{* *}$ & $0.000382 *$ \\
\hline & $(2.458)$ & $(2.115)$ & $(1.929)$ \\
\hline \multirow[t]{2}{*}{ Constant } & $-0.0284 * *$ & $-0.0643 * * *$ & $-0.0360 * * *$ \\
\hline & $(-2.037)$ & $(-3.018)$ & $(-3.055)$ \\
\hline Observations & 146 & 146 & 146 \\
\hline R-squared & 0.532 & 0.453 & 0.4415 \\
\hline Number of id & & 16 & 16 \\
\hline \multicolumn{4}{|c|}{ Robust t-statistics in parentheses } \\
\hline
\end{tabular}

The Table 6 shows that the growth rate of the Internet finance (GIF) is significant at a 1\% significance level and the symbol is negative, which indicates that the increase of the growth rate of Internet finance will significantly reduce the commercial banks' total assets yield. In other words, the rise in the growth rate of Internet finance will reduce the profitability of commercial banks. From the point of view of the control variables, the capital adequacy ratio (CAR) is significant at the $1 \%$ significance level, which indicates that the increase in the capital adequacy ratio will significantly increase the profitability of the commercial banks. The cost to income ratio (CIR) is significant at the $1 \%$ significance level, which indicates that the increase in the cost to income ratio will significantly decrease the profitability of the commercial banks. The net interest margin (NIM) is significant at 1\% significance level, with the coefficient positive, which indicates that the increase in the net interest margin will significantly increase the commercial banks' profitability. The gross domestic product (GDP) rate is significant at $1 \%$ significance level, with the coefficient is negative, which indicates that the increase of the rate of the gross domestic product will significantly decrease the profitability of the commercial banks. The consumer price index (CPI) is significant at a $1 \%$ significance level, with the coefficient posi- 
tive, which indicates that the increase of the consumer price index will significantly increase the commercial banks' profitability.

The total asset of the commercial bank (ASSET) in the control variables stands for the size of the cial banks is significant at the $10 \%$ significance level and the coefficient is positive, which indicates that the increase of the size in the scale of the commercial banks will promote the profitability of the commercial banks, in other words, the larger commercial banks with the better profitability ability.

\subsection{Analysis}

Traditional commercial finance gives people the impression that is slow and complex without enough human services. While Internet finance is the opposite, which is fast, simple, emphasizing the user experience. The difference between traditional commercial banks and Internet finance has several reasons. For traditional commercial banks, there are two reasons. The first is that parts of the traditional commercial banks make a profit through their monopoly on the market. Second, the core of traditional commercial banks is a business risk. The risk tolerance is lower and relatively conservative. Internet finance has a higher tolerance for risk, so that is more convenient for the customers. The rapid development of Internet finance will decrease the profitable ability of commercial banks.

From the above tables, the total asset of the commercial bank stands for the size of the commercial banks is significant at the $10 \%$ significance level. The coefficient is positive, which indicates that the increase of the size in the scale of the commercial banks will promote the profitability of the commercial banks. In other words, the larger commercial banks have the better profitability ability. The small commercial banks have significant external shocks, and the innovation costs are higher than the peers. Thus, the small scale of commercial banks' profitability ability will remarkably affected by the impact of Internet finance. From the side to prove that Internet finance development, reducing the threshold of competition and Internet finance itself has an exact scale effect. Internet finance has dramatic impact on small commercial banks. The results illustrate that the small-sized commercial banks will be suffered more influence from the third payment service based on Internet finance than that of the national large commercial banks.

\section{Conclusion}

Through the theoretical analysis and quantitative analysis of the 16 listed Chinese commercial banks with different sizes, it can be seen that Internet finance has begun to have a significant impact on the commercial banks of different sizes with the continuous development of Internet finance in China. These effects are positive or negative, but it's not immutable. It depends on the size of the commercial banks, development awareness, the main business scope and the degree of Internet finance development. The national large commercial banks have the slowest response in the development of Internet finance. The national small and medium sized commercial banks have benefited the most from the development of Internet finance. In the future, it is possible to further squeeze the market share of large commercial banks and reduce the degree of monopoly of the whole banking industry. The small commercial banks suffered the most severe impact. If they are unable to adapt to the rapid conversion from line off to line on, it may lead operating difficulties or even bankruptcy to several small urban commercial banks. At the same time, it is claimed that the development of Internet finance has promoted the implementation of China's finance, promoted the development of small and medium sized enterprises, reduced the access threshold of the financial industry, expanded the competition, and improved the people's living standard. What's more, Internet finance has brought greater challenges to small and medium sized regional commercial banks.

\section{References}

1. Allen F, McAndrews J, Strahan P. Journal search results-cite this for me. Journal of Financial Services Research 2002; 22(1/2): 5 - 27.

2. Liu T. Research on the risk characteristics and regulation paradigm of internet financial. Applied Mechanics and Materials 2014; p.687 - 691 . 
3. Furst K, Lang W, Nolle D. Internet banking. Journal of Financial Services Research 2002; 22(1/2): 95-117.

4. Russell J. Alipay, China's top mobile payment service, expands to the U.S. 2017. [Internet]. Tech Crunch. Available from: https://techcrunch.com/2017/05/09/alipay-first-data-us-point-of-sale-expansion/ 